\title{
MODIFICATIONS OF THE VAGAL EFFECT ON THE HEART AND THE CARDIAG METABOLISM BY RESERPINE IN VITRO
}

\author{
NOBORU TODA, MOTOHATSU FUJIWARA AND KEISUKE HATTORI \\ Department of Pharmacology, Faculty of Medicine, Kyoto University, Sakyo-ku, Kyoto \\ Received for publication January 16, 1965
}

The previous reports from this laboratory $(1-4)$ have shown that reserpine in a concentration of $10^{-5} \mathrm{~g} / \mathrm{ml}$ results in a decrease in the amplitude and prolongation of dcpolarization and repolarization phases of transmembrane action potential and sometimes an arrest of rhythmic contraction in the isolated rabbit atria. The finding that noradrenaline restarts the atrial beat which has becn arrested by reserpine led us to the assumption that endogenous noradrenaline may play an important role in the intrinsic rhythmicity of the heart. However, there has been presented evidence against this assumption $(5,6)$. The arrested atria can be restarted by noradrenaline without significant increase in the level of tissue noradrenaline. By contrast, the atria from the rabbit prctrcatcd with reserpine and depleted of noradrenalinc continue to contract long after isolation. Consequently, it has been postulated that the cardiac inhibitory effects of reserpine in vitro do not derive from a decrease in the amount of endogenous catecholamines but from some dircct action of unknown mechanism (4).

In the course of experiments studying the effects of adrenergic drugs on the atrial response to stimulation of the vagus nerve, Toda et al. (7) have found that a deficiency of oxygen supply results in a potentiation of the vagal response without modifying acetylcholine response and this is similar to that of reserpine. Reserpine reduces oxygen consumption of the isolated rabbit intestine (8) and the rat brain homogenate as well as liver and kidney slices (9). The present experiments were designed to ascertain whether a close relationship exists between the cardiac inhibitory effect and the depression of tissue respiration following reserpine in iitro.

\section{METHODS}

Preparation of isolated guinea-pig atria with the vagus nerve: 'The procedures to make the vagus-atrial preparation, to stimulate the vagus nerve, to record the chronotropic and inotropic responses and to compose the nutrient medium in which the preparation was suspended were described in the previous report $(10)$.

Measurement of oxygen consumption: Rabbits of either sex wcighing from 1.8 to $2.3 \mathrm{~kg}$ were used. To obtain preparations of ventricle, the animals were killed by bleeding and the heart was rapidly removed. The right and left ventricles were separated from 
the atria and wcighed. $\Lambda 25 \%$ suspension was preparcd by grinding the ventricles in a glass homogenizer with ice-cold Krebs solution. Oxygen consumption was determined by the Warburg direct manometric method at $37.5^{\circ} \mathrm{C}$ using an atomosphere of air. The main chamber of each Warburg flask contained $2.0 \mathrm{~mL}$ of the tissuc suspension. The center contained $0.2 \mathrm{ml}$ of $4 \mathrm{~N} \mathrm{KOH}$. The side arm contained $0.5 \mathrm{ml}$ of reserpine solution to give the final flask concentration of $10^{-5} \mathrm{~g} / \mathrm{ml}$ after tipping, or an equivalent volume of phosphoric acid control solution. Immediately after temperature equilibration, or 1 and 2 hours after preincubation, the content of side arm was tipped into the main chamber and readings were taken at 10-minute intervals for 1 hour. Results are expressed in terms of oxygen uptake in $\mu$ per g wet weight of tissue at each time. With reserpine in vivo, the atrial homogenate was employed for the detcrmination of oxygen uptake. Readings were made at 10-minute intcrvals for 1 hour immediately after temperature equilibration without tipping from the side arm.

Drugs employed were reserpine, $\mathrm{KCN}, 2,4$-dinitrophenol, procaine hydrochloride, quinidine sulfate and disodium ethylenediamine tetraacetate.

\section{RESULTS}

\section{Negalive Chronotropic and Inotropic Responses of the Vagus-Atrial Preparation}

\section{Reserpine}

In confirmation of Tachi's observations (3), a concentration of $10^{-5} \mathrm{~g} / \mathrm{ml}$ of reserpine resulted in gradual decreases in rate and amplitude of atrial contraction from about 5 minutes until a complete arrest which occurred within 2 hours in most preparations. As shown in Fig. $1 \mathrm{~A}$, the decrease in the amplitude (broken line) was more than that in the rate (sodid line).

In the course of depression of the spontaneous contraction, the negative chronotropic and inotropic responses (solid and broken line, respectivcly) to the vagal stimulation were rather slightly augmented in the initial stage, then fell to a level near the control (Fig. $1 \mathrm{~B})$.

Only when the depression of spontaneous contraction was not so marked, somewhat recovery in contractile force was obtaincd by washing. However, the rcsponses to the vagal stimulation were not restored by washing.

In the presence of reserpine in the concentration of $10^{-5} \mathrm{~g} / \mathrm{ml}$, which was enough to depress the spontaneous contraction of the atria, the addition of adrenaline in a concentration of $5 \times 10^{-\tau}$ to $10^{-1} \mathrm{~g} / \mathrm{ml}$ or noradrenaline in a concentration of $10^{-6}$ to $2 \times 10^{-6}$ $\mathrm{g} / \mathrm{ml}$ did augment the contraction transiently but not alter the atrial responses to the vagal stimulation. On the other hand, after removing reserpine from the bath adrenaline or noradrenaline restored the vagal responses as well as spontancous contraction of the atria.

2. $K C N$

A concentration of $10^{-5} \mathrm{~g} / \mathrm{ml}$ of $\mathrm{KCN}$ only slightly reduced the rate of spontaneous contraction of the atria, while it markedly decreased the amplitude (Fig. 2 A). The 

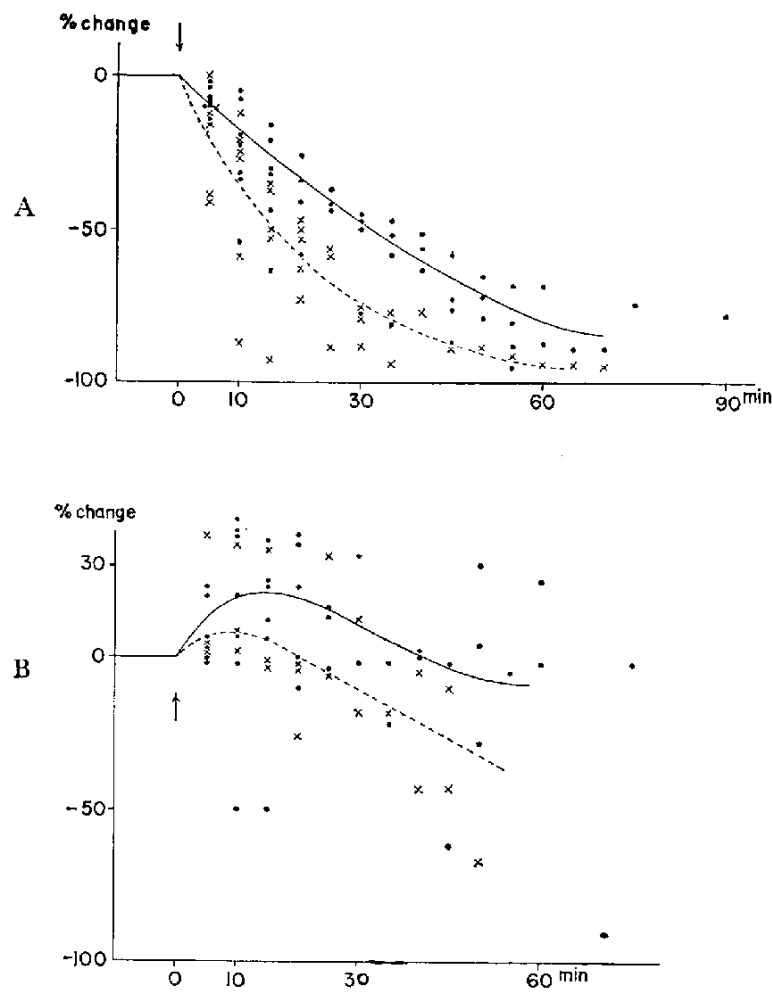

FiG. 1. A. Effects of reserpine $10^{-5} \mathrm{~g} / \mathrm{ml}$ on the rate (-).) and amplitude ( $x-\cdot \cdot x)$ of spontaneous contraction of isolated guinea-pig vagus-atrial preparation. B. The same as $A$ but on the negative chronotropic (.-.) and inotropic $(x-\cdots)$ ) responses to stimulation of the vagus nerve.

Ordinates, percentage changes in spontaneous contraction and ncgative responses, as compared with those before reserpine; abscissae, time in minutes after application of reserpine at arrow.
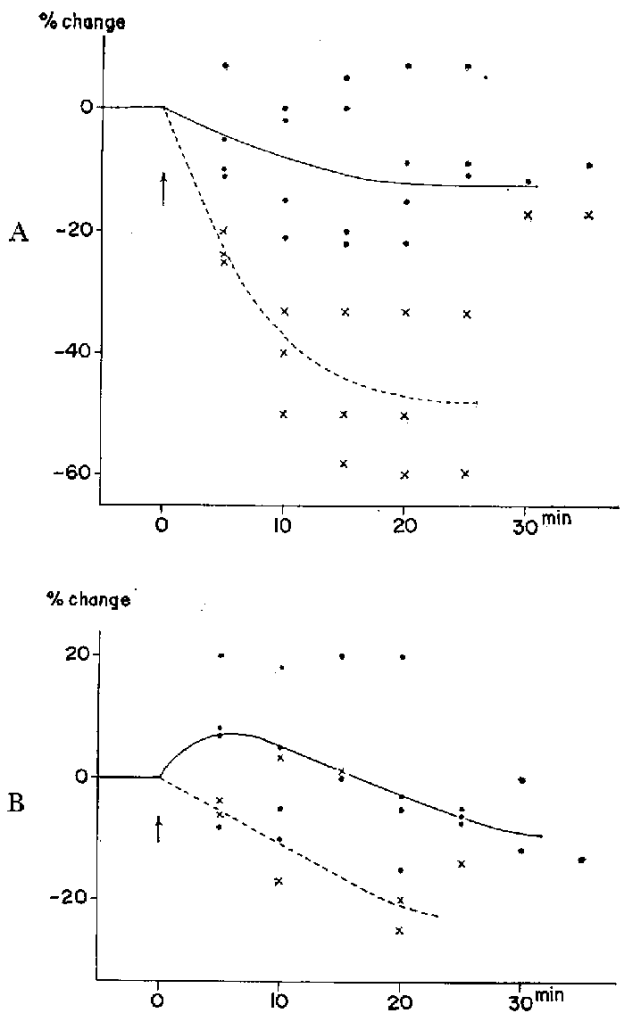

Fir. 2. A. Effects of KCN $10^{-5} \mathrm{~g} / \mathrm{ml}$ on the rate (--.) and amplitude $(\times--x)$ of spontaneous contraction of isolated guinea-pig vagus-atrial preparation. B. The same as $\mathbf{A}$ but on the negative chronotropic (*-) and inotropic $(x \cdot-\cdot x)$ responses to stimulation of the vagus nerve.

Ordinates, percentage changes in spontaneous contraction and negative responses, as compared with those before KCN ; abscissae, time in minutes after application of $\mathrm{KCN}$ at arrow.

negative chronotropic response to the vagal stimulation was augmented 10 to $20 \%$ at 5 to 10 minutes, and this initial augmentation was followed by a gradual return to the control within 30 minutes. The results are illustrated in Fig. 2 B, and thus qualitatively similar to that caused by reserpine. However, the negative inotropic response after the same concentration of KCN showed a gradual decrease without the initial augmentation.

In a higher concentration of $3 \times 10^{-5} \mathrm{~g} / \mathrm{ml}$ of $\mathrm{KCN}$, the decrease in rate and amplitude of spontaneous contraction occurred more rapidly and profoundly than that caused by $10^{-5} \mathrm{~g} / \mathrm{ml}$. The negative chronotropic response to stimulation was initially augmented but then rapidly fell to a profound depression, the decrease being 35 to $50 \%$ below the control at 20 minutes. The negative inotropic response showed no initial augmentation 
and the subsequent decrease occurred morc rapidly and profoundly than that caused by $10^{-5} \mathrm{~g} / \mathrm{ml}$.

Unlike after reserpine, KCN-depressed spontancous contraction and vagal responses of the atria were almost completely restored by washing, and occasionally the vagal responses reached the level 10 to $15 \%$ above controls.

\section{2,4-Dinitrophenol (DNP)}

A concentration of $10^{-5} \mathrm{~g} / \mathrm{ml}$ of DNP produced slight but variable changes in rate of spontaneous contraction of the atria within 15 minutes, and then a gradual but consistent decrease. On the other hand, the same concentration of DNP resulted in a rapid and profound decrease in amplitude, the decrease being about $60 \%$ and $90 \%$ at 5 and 20 minutes, respectively (Fig. $3 \mathrm{~A}$ ). The negative chronotropic response to the vagal stimulation was augmented about $10 \%$ at 10 minutes after DNP and then the augmentation turned to a gradual decrease, in a manner somewhat similar to the course after reserpinc. The negative inotropic response was only slightly and variably modificd, and the mean percent change was within $10 \%$ of the control (Fig. $3 \mathrm{~B}$ ).

The depression of the spontancous contraction was reversible after washing, and an almost complete rccovery was obtained about 60 minutes later. On the other hand, wash-
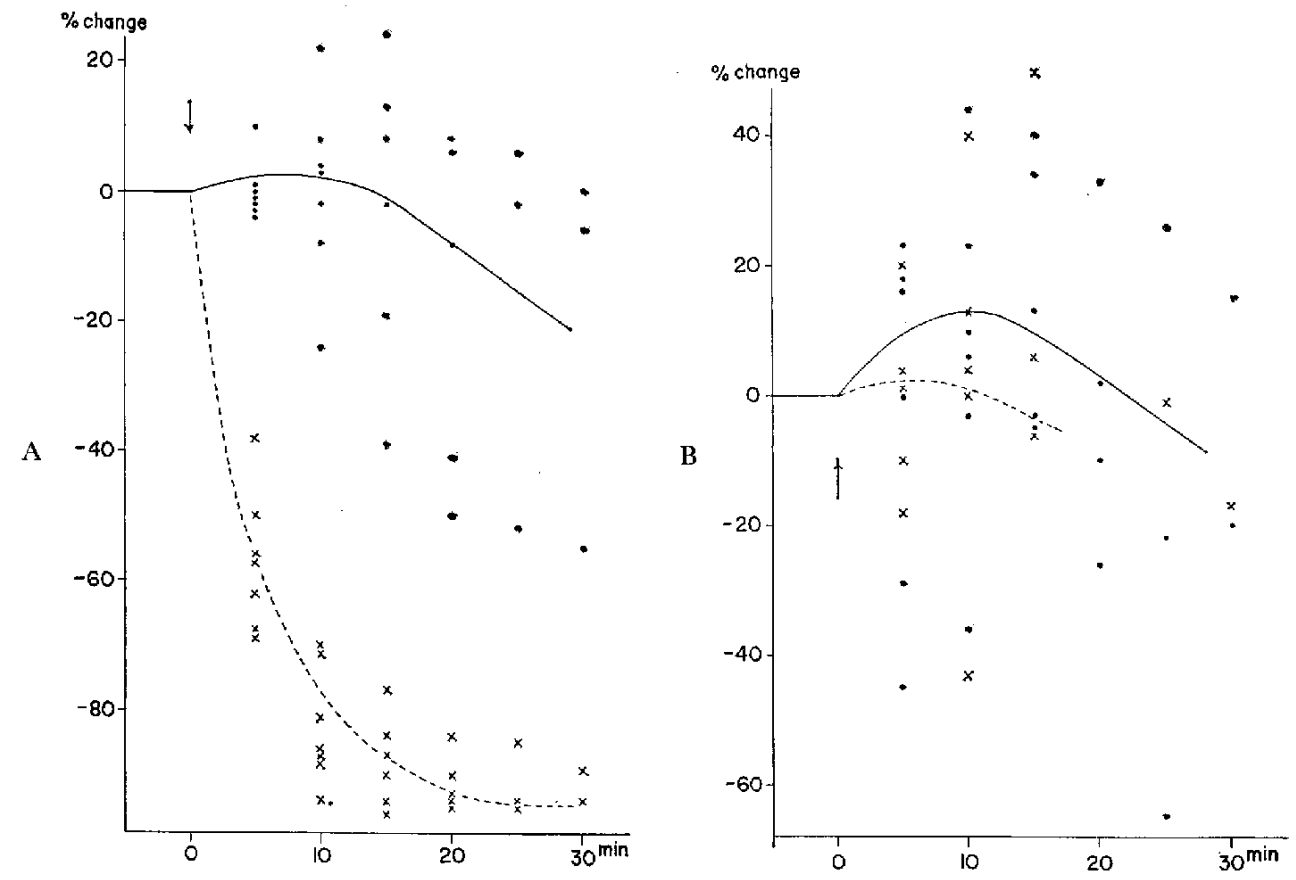

FIG. 3. A. Effects of DNP $10^{-5} \mathrm{~g} / \mathrm{ml}$ on the rate (.-.) and amplitude ( $x$-.- $\left.x\right)$ of spontaneous contraction of isolated guinea-pig vagus-atrial preparation. $B$. The same as $A$ but on the negative chronotropic (.-.) and inotropic $(x \cdot-\cdot)$ responses to stimulation of the vagus nerve.

Ordinates, percentage changes in spontaneous contraction and negative responses, as compared with those before DNP; abscissae, time in minutes after application of DNP at arrow. 
ing did not restore the responses to the vagal stimulation within 30 to 40 minutes, and usually more than 60 minutes were required for restoring the responses.

\section{Procaine and quinidine}

Since quinidine somewhat resembles reserpine in that they prolong the depolarization and repolarization phases of atrial action potential (11-13), the effects of procaine and quinidinc were tested on the vagus-atrial preparation. Procaine somewhat reduced the rate and amplitude of the spontaneous contraction. The decreases werc about $10 \%$ with $10^{-5} \mathrm{~g} / \mathrm{ml}$ and $20 \%$ with $5 \times 10^{-5} \mathrm{~g} / \mathrm{ml}$. The negative inotropic and chronotropic responses to the vagal stimulation decreased immediately aftcr addition of procaine $2 \times 10^{-6} \mathrm{~g} / \mathrm{ml}$ without initial augmentation, and the decreases in amplitude and rate at 10 minutes were

A

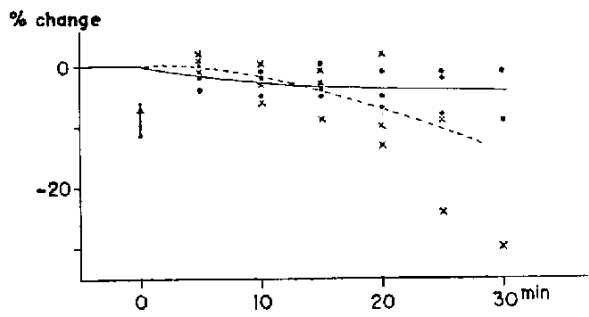

B

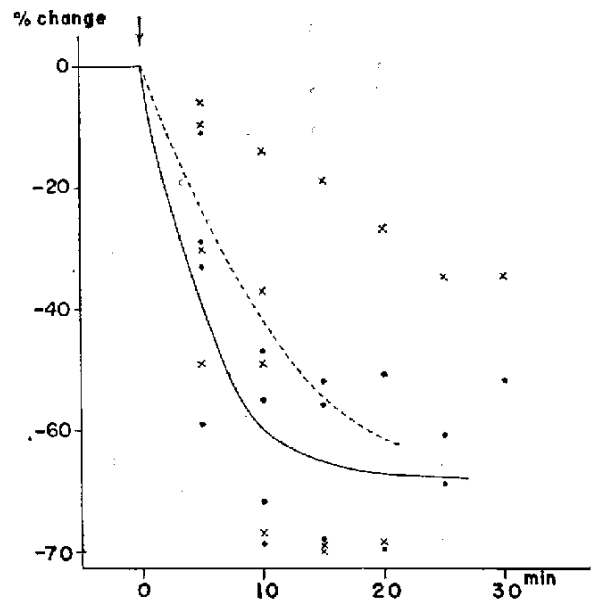

Fig. 4. A. Effects of procaine $2 \times 10^{-6} \mathrm{~g} / \mathrm{ml}$ on the rate $(\cdot-\cdot)$ ) and amplitude $(x-\cdots)$ of spontaneous contraction of isolated guinea-pig vagus-atrial preparation. B. The same as $\mathrm{A}$ but on the negative chronotropic (.-..) and inotropic ( $(x-.-x)$ responses to stimulation of the vagus nerve. No initial augmentation occurs.

Ordinates, percentage changes in spontaneous contration and negative responses, as compared with those before procaine; abscissae, time in minutes after application of procaine at arrow.
$\Lambda$

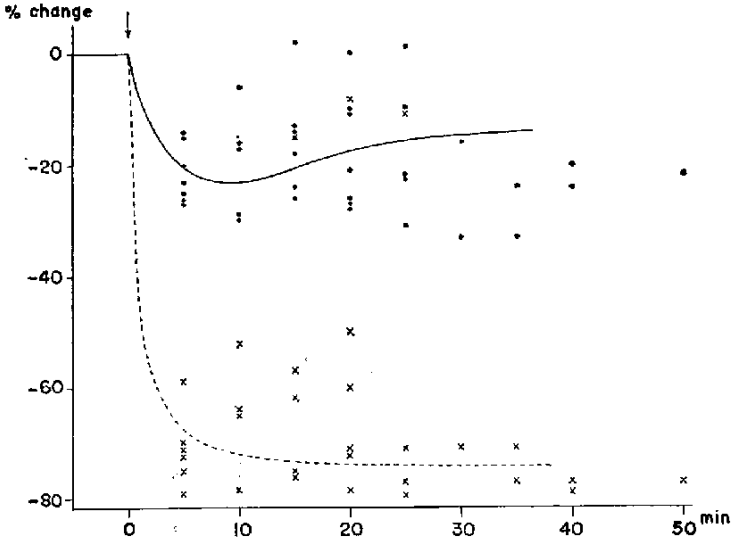

B

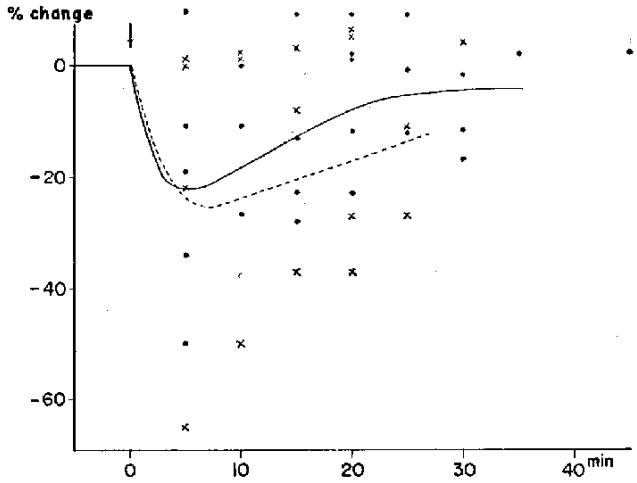

FIs. 5. A. Effects of diNa-EDTA $0.82 \mathrm{mM}$ on the rate (.-.) and amplitude $(x---x)$ of spontaneous contraction of isolated guinea-pig vagus-atrial preparation. B. The same as $\mathrm{A}$ but on the negative chronotropic (.-.) and inotropic ( $(-\cdots x)$ response to stimulation of the vagus nerve. No initial augmentation occurs.

Ordinates, percentage changes in spontaneous contraction and negative responses, as compared with those before diNa-EDTA; abscissae, time in minutes after application of diNa-EDTA at arrow. 
about $40 \%$ and $60 \%$, respectively (Fig. $4 \mathrm{~B}$ ). When depressed by procaine, the atrial responses to the vagal stimulation were never increased even with 2 to 4 times the stimulus intensity prior to procaine. Raising the concentration of procaine to $10^{-5} \mathrm{~g} / \mathrm{ml}$ and $5 \times 10^{-5} \mathrm{~g} / \mathrm{ml}$ resulted in a $90 \%$ depression and complete inhibition of the vagal responses, respectively.

The depression of the spontaneous contraction as well as that of the vagal responses was casily reversed by washing, and the initial response was obtained about 30 minutes after washing.

Procaine $2 \times 10^{-\pi} \mathrm{g} / \mathrm{ml}$ resulted in a $10 \%$ decrease of the ncyative inotropic response to added acetylcholine $10^{-8}$ to $10^{-6} \mathrm{~g} / \mathrm{ml}$, but littlc modified the chronotropic response. Raising the concentration of procaine to $5 \times 10^{-5} \mathrm{~g} / \mathrm{ml}$ led to almost complete abolition of both responses to added acetylcholinc.

Quinidine $10^{-5} \mathrm{~g} / \mathrm{ml}$ produced a 10 to $20 \%$ decrease in rate of the spontaneous contraction but little modified the amplitude. From 15 minutes after quinidine, however, the negative inotropic and chronotropic responses to the vagal stimulation were depressed 60 to $80 \%$ and 70 to $90 \%$, respectively. The negative responses to added acetycholine were also markedly dcpressed by quinidinc.

\section{Disodium ethylenediamine tetraacetate (DiNa-EDTA)}

In order to find whether any similarities exist between the effects of calcium deficiency and reserpine in the vagus-atrial preparation, the experiment was done employing diNa-EDTA in the concentration of $0.82 \mathrm{mM}$ which is a half of molar concentration of calcium in the nutrient solution. The results are illustrated in Fig. 5 A. While a dccrease in rate of the spontaneous contraction is at maximum about $20 \%$, the amplitude was rapidly and profoundly decreased after diNa-EDTA and from 5 minutes onward a 70\% depression was maintained. However, the depression was easily reversed by addition of $\mathrm{CaCl}_{2} \quad 0.82$ to $1.64 \mathrm{mM}$. The atrial resposes to the vagal stimulation were variably modified by diNa-EDTA, but in average about $20 \%$ depression occurred at 5 minutes and then the responses somewhat recovered toward the control level. Unlike reserpine, the initial augmentation did not occur after diNa-EDTA (Fig. 5 B). In the presence of diNa-EDTA, the addition of 0.82 to $1.64 \mathrm{mM}$ of $\mathrm{CaCl}_{2}$ could not restore the depressed vagal responses.

TABLE 1. Effects of reserpine $10^{-5} \mathrm{~g} / \mathrm{ml}$ on the oxygen uptake of rabbit ventricle homogenate.

\begin{tabular}{|c|c|c|c|c|c|c|}
\hline $\begin{array}{l}\text { Preincubation } \\
\text { time (hr) }\end{array}$ & Solution & $\begin{array}{c}\text { No. of } \\
\text { observations }\end{array}$ & 10 & $\begin{array}{c}\text { Incubation } \\
20\end{array}$ & time $\underset{40}{(\min )}$ & 60 \\
\hline \multirow{2}{*}{0} & Control & 8 & $21.38 \pm 0.88$ & $32.79 \pm 1.66$ & $47.25 \pm 4.46$ & $55.82 \pm 8.14$ \\
\hline & Reserpine & 5 & $19.17 \pm 1.45$ & $29.29+0.54$ & $41.92=3.20$ & $50.60+3.42$ \\
\hline \multirow[t]{2}{*}{1} & Control & 4 & $12.72 \pm 2.50$ & $19.58+2.96$ & $26.15+3.64$ & $30.20+4.99$ \\
\hline & Reserpine & 4 & $10.26 \pm 2.18$ & $16.05 \pm 1.86$ & $21.92 \pm 2.44$ & $25.80 \pm 5.08$ \\
\hline \multirow[t]{2}{*}{2} & $\{$ Control & 5 & $7.82 \pm 1.19$ & $13.53 \pm 0.79$ & $21.35 \pm 2.58$ & $29.08 \pm 5.49$ \\
\hline & Reserpine & 5 & $7.67 \pm 1.70$ & $11.98=1.88$ & $20.25+3.80$ & $26.73+5.68$ \\
\hline
\end{tabular}

Oxygen uptake is given in $\mu 1-\mathrm{S}$.E./g wet tissue. 
After washing, the spontancous contraction depressed by diNa-EDTA was easily restored, the recovery being more complete in rate than amplitude. The atrial responses also recovered by washing.

\section{Tissue Respiration}

The effect of $10^{-5} \mathrm{~g} / \mathrm{ml}$ of reserpine on the oxygen consumption of rabbit ventricle homogenate is shown in Table 1 and Fig. 6. After 0-, 1- and 2-hour preincubation, reserpine did not significantly modify the oxygen uptake of rabbit ventricle when compared with the corresponding controls $(\mathbf{P}>0.05)$.

Experiments were also made with reserpine in vivo. The heart was removed 3 and 16 hours after the intravenous injection of $1.0 \mathrm{mg} / \mathrm{kg}$ of reserpine into rabbits, and atrial homogcnates of the heart wcrc cmployed for the determination of oxygen uptake. The preparations from rabbits treated with reserpine 3 and 16 hours previously showed $42 \%$ and $31 \%$ decreases $(\mathrm{P}<0.05)$ of oxygen uptake after a 1-hour incubation time (Table 2).

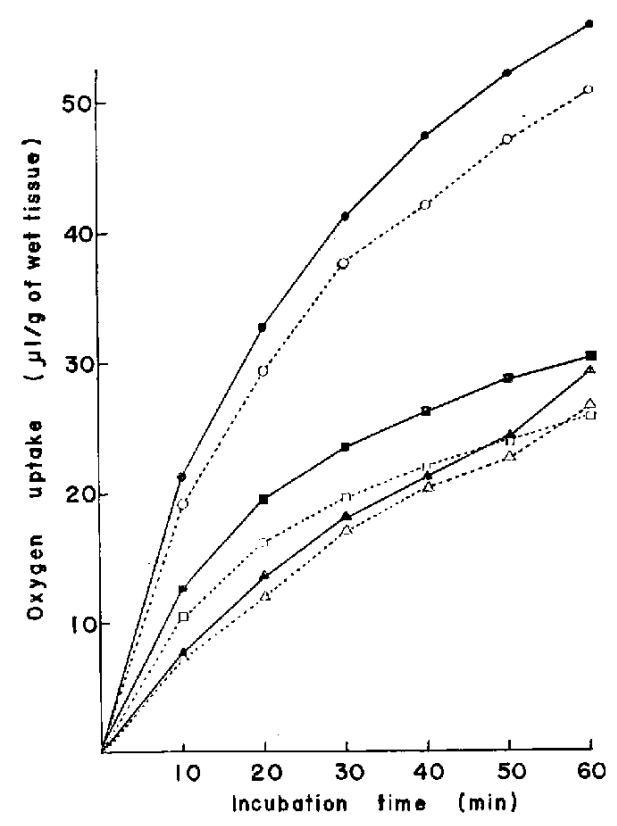

Fir. 6. Warburg experimcnts. Measurements of oxygen uptake by rabbit ventricle homogenate.

In control solution - - and reserpine $10^{-5} \mathrm{~g} / \mathrm{ml}$ o... immediately after temperature equilibration; in control solution -.- and reserpine $10^{-5} \mathrm{~g} / \mathrm{ml}$ 口... after a 1-hour preincubation; and in control solution $\Delta_{-} \Delta$ and reserpine $10^{-5} \mathrm{~g} / \mathrm{ml} \wedge \cdots$ after a 2-hour preincubation.

TABIE 2. Oxygen uptake of rabbit atrial homogenate after intravenous injection of reserpine $1.0 \mathrm{mg} / \mathrm{kg}$.

\begin{tabular}{ccccc}
\hline Control & $3 \mathrm{hr}$ after reserpine & \multicolumn{1}{c}{$16 \mathrm{hr}$ after reserpine } \\
$\mathrm{O}_{2}$ uptake & $\mathrm{O}_{2}$ uptake & $\%$ Change & $\mathrm{O}_{2}$ uptake & $\%$ Change \\
213.2 & 121.0 & 42.1 & 150.0 & 30.8 \\
+5.56 & +8.39 & & +19.5 & \\
$(5)$ & $(5)$ & & $(4)$ \\
\hline
\end{tabular}

Oxygen uptake is given in $\mu I+$ S.E./g wet tissue at a 1-hour incubation.

The figures in parentheses represent the number of observations.

\section{DISCUSSION}

Results of the cxperiments described here indicate that reserpine decreases the rate and amplitude in spontaneous beat of the isolated guinea-pig atria but initially augments the negative chronotropic and inotropic responses to stimulation of the vagus nerve. 
These effects are similar to those of deficiency of oxygen supply (7). The effects of $\mathrm{KCN}$ somewhat resemble those of reserpine and oxygen deficiency in that the negative chronotropic response is augmented while the amplitude of spontaneous contraction is decreased. Toda et al. (7) have shown that an addition of potassium chloride to the bath rcsults in the augmentation of the negative chronotropic and inotropic responses of the isolated atria to stimulation of the vagus nerve. Thus it seems likely that an application of rescrpine as well as $\mathrm{KCN}$ may result in tissue anoxia with a subsequent increase in outflux of intraccllular potassium ion, which in turn augments the negative responses to the vagal stimulation. In fact, rescrpine $5 \times 10^{-5} \mathrm{~g} / \mathrm{ml}$ has been reported to decrease the oxygen consumption of isolated rabbit intestine and increase the release of potassium ion from frog sartorius muscle (8). Anoxemia also results in an increased outflux of potassium ion from the heart (14).

Nevertheless, the effect of KCN differs from that of reserpine in that the initial augmentation of negative responses to the vagal stimulation turns to a decrease more rapidly than after reserpine, and the $\mathrm{KCN}$-depressed responses are easily reversed by washing. In addition, when arrested by excess potassium ion the atria often restore the spontancous beat following stimulation of the vagus nerve (7), but the reserpinearrested atria do not so. Rescrpine $10^{-5} \mathrm{~g} / \mathrm{ml}$ decreases the oxygen consumption of rabbit ventricle homogenate insignificantly, although it does markedly decrease that of atrial homogenate when administered intravenously. The depressant effect of reserpine on tissue respiration appears to be highly dose-dependent. However, rcports from several investigators are compatible with each other in that the concentration of reserpine required to significantly decrcase oxygen consumption is a range from $2 \times 10^{-5}$ to $2 \times 10^{-4}$ $\mathrm{g} / \mathrm{ml}(8,9,15)$. It has been postulated previously that the ability of reserpine to deplete catecholamincs from rabbit atria is extremely different between in vitro and in vivo administrations, and the extent of noradrenaline depletion after reserpine in vitro is too small to explain the depressant action of reserpine on the isolated atria (4). On the basis of the indirect cvidence presented here, it is also unlikely that the inhibition of oxygen consumption may be primarily responsible for the direct action of reserpine on the isolated atria.

The effccts of DNP, an uncoupler of oxidative phosphorylation, resemble those of reserpine in that the atrial responscs to the vagal stimulation are initially augmented and the subsequent depression is difficult to reverse by washing. Abood and Romanchek (16) have shown that reserpine $2 \times 10^{-5} \mathrm{M}$ produces over $40 \%$ inhibition in $\mathrm{P} / \mathrm{O}$ of rat brain mitochondria, comparable with the most potent uncoupling agents. Further studies are required to ascertain whcther the direct depressant action of reserpine on the isolated atria derives from uncoupling of oxidative phosphorylation.

Electrophysiological studies have revealed that reserpine given in vitro reduces the action potential and prolongs its duration in the rabbit atria $(1,2)$, while either anoxia or KCN reduces the action potcntial but shortens its duration $(17,18)$. DNP $10^{-6}$ to $4 \times 10^{-5} \mathrm{~g} / \mathrm{ml}$ also has been reported to shorten the repolarization phase without modifying 
the resting and action potentials (13). In contrast, quinine $10^{-5}$ to $5 \times 10^{-5} \mathrm{~g} / \mathrm{ml}$ behaves as reserpine, reducing the overshoot and prolonging the repolarization phase (13). However, the present results obtained with quinidine and procaine indicate that unlike reserpine, these agents decrease the spontaneous contraction only slightly and produce an easily reversible depression of the atrial responses to the vagal stimulation. In addition, quinidine and procaine markedly depress the negative chronotropic and inotropic responses to added acetylcholine. The findings that reserpine, unlike these agents, does not modify the rcfractory period (unpublished observations) also cxclude the possibility of quinidinelike action of reserpine.

The essential role of calcium ion in the process of muscle contraction is well known. The addition of diNa-EDTA which chelates calcium ion in the bath fluid differs from reserpine in that the initial augmentation of the vagal responses does not occur.

It is worthwhile to draw attention to the reports that barbiturates prolong the total duration without modifying the amplitude of resting and action potentials of the heart (13), and that barbiturates have a depressant action of oxygen uptake (19) and an uncoupling action of oxidative phosphorylation (20). From the viewpoint of clcctrophysiological and metabolic changes, further studies arc in progress to compare the reserpine action with the barbiturate action.

\section{SUMMARY}

The cardiac inhibitory effects of reserpine were studied, comparing with those of KCN, 2,4-dinitrophenol, procaine, quinidine and diNa-EDTA.

In the isolated guinea-pig vagus-atrial preparation, reserpine $10^{-5} \mathrm{~g} / \mathrm{ml}, \mathrm{KCN} 10^{-5}$ to $3 \times 10^{-5} \mathrm{~g} / \mathrm{ml}, 2,4$-dinitrophenol $10^{-5} \mathrm{~g} / \mathrm{ml}$ and diNa-EDTA $0.82 \mathrm{mM}$ decreased the amplitude of spontaneous contraction morc profoundly than the rate. Quinidine and procaine up to $5 \times 10^{-5} \mathrm{~g} / \mathrm{ml}$ only slightly decreased the rate and amplitude.

Reserpine and 2,4-dinitrophenol initially augmented, then decreased the negative chronotropic and inotropic responses to stimulation of the vagus nerve. KCN initially augmented the negative chronotropic response but not the negative inotropic response. Procaine, quinidine and diNa-EDTA decreased both responses without any initial augmentation.

Reserpine $10^{-5} \mathrm{~g} / \mathrm{ml}$ insignificantly modified the rate of respiration of rabbit ventricle homogenate. The intravenous injection of reserpine $1.0 \mathrm{mg} / \mathrm{kg}$ markedly depressed the rate of respiration of rabbit atrial homogenate.

The mechanism of the direct cardiac inhibitory action of reserpine other than catecholamine depletion is discussed.

\section{REFERENCES}

1) Toda, N. : This Journal 10, 78 (1960)

2) TonA, N. : rbid. 12, 93 (1962)

3) TACHI, S. : Folia pharmacol. japon. 58, 449 (1962) (Japanese)

4) FujIwara, M. : Proceedings of the 16th General Assembly of the Jafian Mediral Congress in Osaka 1, 228 
(1963) (Japanese)

5) Matsuo, T. : This Journat, 12, 62 (1962)

6) Matslo, T. and TAGHi, S. : Ibid. 12, 191 (1962)

7) Toda, N., Fujiwara, M. and Simmamoto, K. : Ibid. 14, 118 (1964)

8) Git.IS, C.N. AND Lewis, J.J. : Brit. J. Pharmacol. 12, 517 (1957)

9) KiRPEKAR, S.M. ANI) L.EW1s, J.J. : Ibid. 14, 40 (1959)

10) Toda, N., Fujinara, M. and Shimamoto, K. : This Journal 14, 412 (1964)

11) Matsumura, M. and Takaori, S. : 16id. 8, 143 (1959)

12) West, T.G. A.No Amory, D.W. : J. Pharmacol. 130, 183 (1960)

13) LÜllmann, H. : Arch. exp. Path. Pharmak. 237, 447 (1959)

14) Rudi, T.C. A.vd Fultox, J.F. : Medical Physiology and Biophysics p. 634, W.B. Saunders Co., Philadelphia (1960)

15) Draskóczy, P.R., Burack, W.R. and Weiner, N. : J. Pharriacui. 141, 58 (1963)

16) АвоOD, G. AND RomancheK, L. : Ann. N.Y. Acad. Sci. 66, 812 (1957)

17) WeBb, J.L. and Hollander, P.B. : Circulation Res, 4, 618 (1956)

18) Webr, J.L. and Hot.lander, P.B. : lhid. 7, 131 (1959)

19) QUAstel, J.H. : Anesth. and Analg. 31, 151 (1952)

20) Brony, T.M. and Bain, J.A.: Proc. Soc. exp. Biol, N.Y. 77, 50 (1951) 